\title{
PARATODOS BAHIA: UMA ORGANIZAÇÃO NO JOGO DO BICHO
}

Jair Nascimento Santos*

\section{RESUMO}

Este trabalho é resultado do estudo da PARATODOS BAHIA, uma organização contraventora, que gere de forma monopolista o jogo do bicho nas cidades de Salvador e Lauro de Freitas, ambas na Bahia. O interesse em analisá-la, advém do fato da mesma apresentar peculiaridades não encontradas nas organizações comumente estudadas, bem como revelar a ambiguidade de uma Sociedade que ao mesmo tempo condena e pratica o ilícito. $\mathrm{Na}$ abordagem deste texto analisamos o objeto à luz do imaginário simbólico, da formação de redes e da liderança, todos como mecanismos indispensáveis à sobrevivência e permanência da organização no tempo e no espaço, principalmente pelo caráter virtual adquirido no decorrer da prática da atividade.

PALAVRAS CHAVES: Contravenção, redes organizacionais, liderança, imaginário simbólico, ambiguidade, virtualidade.

* Mestre em Administração (UFBA) e Professor da UEFS: 


\section{Introdução}

O presente trabalho é um substrato de dissertação, resultante da análise da organização PARATODOS BAHIA, uma empresa baiana cuja atividade está voltada para o ordenamento e gestão do jogo do bicho nas cidades de Salvador e Lauro de Freitas.

O fato do jogo do bicho ser uma atividade ilícita, citada no Código Penal Brasileiro como contravenção penal, e por ser gerido atualmente de forma monopolista pela PARATODOS BAHIA, despertou-nos, mais ainda, o interesse em estudar tal organização no que se refere a sócio-estrutura, liderança, redes organizacionais e seu caráter inovativo.

O estudo desse tipo de atividade é escasso, pois os que existe sobre organizações, em sua quase totalidade, está voltado a organizações legais cujo ethos é legitimado pela Sociedade, resultando em insuficiência de material bibliográfico específico. Creditamos isso ao preconceito discriminativo em relação às pessoas envolvidas com a atividade, haja vista que, paradoxalmente, tal fato não se reverte da mesma forma àqueles que jogam, ou seja, apostam a sorte no jogo do bicho.

A PARATODOS BAHIA foi criada em 04/06/1990, sem registro legal, para gerir de forma monopolista o jogo do bicho nas cidades de Salvador e Lauro de Freitas na Bahia, explorando uma atividade ilícita, citada no Código Penal Brasileiro através do art. 58 como contravenção penal, passivel de prisão e multa, desde o ano de 1941 . Portanto trataremos de uma organização contraventora, que congrega quarenta e três sócios-cotistas com os mais diversos percentuais de participação, fato este desconsiderado nos momentos de decisão colegiada, quando o voto de cada um tem o mesmo peso. Conta, hoje, com mais de dez mil postos de trabalho diretos, amparados por um sistema próprio de assistência e benefícios sociais, extensivos às famílias dos empregados.

A organização tem uma sede própria na orla marítima de Salvador e de lá espalhase pelas duas cidades através de 20 centrais e 2215 pontos em 151 bairros de Salvador e 2 em Lauro de Freitas. Essa extensa malha, própria, além de outras constituídas com as mais diversas instituições, formam a rede da PARATODOS BAHIA. Uma rede virtualizada (Davidow e Malone, 1993) devido à ilicitude da organização.

Constatado esse contexto, identificamos uma questão: como uma organização contraventora sobrevive e permanece no tempo? Visando respondê-la, baseamo-nos em três hipóteses:

jogo como fator de sedução do imaginário popular, visto serem dotados de imaginação simbólica e alegórica aqueles que se dispõem a comprá-lo, especialmente o jogo do bicho;

formação de uma rede organizacional com característica de 
virtualidade, face às múltiplas relações mantidas com diversas organizações legais e ilegais;

liderança como base para construção e manutenção do ethos organizacional, tanto na implantação e valores quanto na implementação da visão num contexto de rede.

No sentido de desenvolver a pesquisa buscamos entender : a) a evolução da organização e sua interação com o meio, incluindo as decisões sócio-políticas pró e contra ao jogo do bicho; b) evolução da sócio-estrutura da organização, enquanto reflexo das interações com o meio, proporcionada pela interligação das redes organizacionais: governo (fiscalização e policiamento), entidades filantrópicas e várias outras instituições; c) evolução da sócio-estrutura sob a ótica da gestão, arquitetura organizacional, práticas e procedimentos.

"Configurado o cenário, focaliza-se a figura dos fundadores: suas histórias e seus papéis nas transformações do presente. Por isso utilizamos recursos metodológicos de pesquisa qualitativa para análise de organização, atentando para as especificidades de macro-cultura baiana, a exemplo das pesquisas já efetuadas por Siqueira, 1993; Fischer et alli, 1993; Risério, 1992; Dantas, 1992." (Fischer e Santos, 1994).

\section{O Jogo do Bicho: Origens e Transformações}

O jogo do bicho surgiu no Brasil no final do século XIX, mais precisamente no ano de 1893, na cidade do Rio de Janeiro, quando o Barão de Drummond era proprietário de um Jardim Zoológico custeado com seus próprios recursos. Após alguns anos de dificuldades financeiras para alimentar os animais e manter o Jardim, requereu à Câmara dos Deputados uma subvenção para evitar que o Zoológico fechasse. Sem obter resposta, enviou outro requerimento sugerindo que 1 ou $2 \%$ da arrecadação bruta das apostas nas corridas de cavalos fossem destinadas ao Zôo, isto sem mexer nos bolsos do contribuinte. A sugestão não foi aceita pela Comissão de Orçamento e pela Câmara, mas concederam ao zoológico a subvenção de dez contos de reis anuais que não davam para cobrir nem a metade das reais necessidades do Zôo.

Assim, na iminência de fechar o Jardim por falta de fundos para a manutenção, o Barão aceita a idéia de um mexicano chamado Manuel Ismael Zevada, seu auxiliar, "que bancava por conta própria um tal Jogo das Flores, na Rua do Ouvidor" (Vianna, 1990), no qual cada uma das flores recebia um número de acordo com uma tabela; assim transpôs-se o jogo da seguinte forma: ao adquirir um ingresso de mil de réis para o Zôo, o comprador concorreria ao prêmio de vinte mil réis caso o animal desenhado no bilhete coincidisse com o mesmo que seria exibido em um quadro algumas horas depois no interior do zoológico. Para tanto, o Barão mandara desenhar 
vinte e cinco animais diferentes e a cada tarde um quadro diferente ou repetido era exibido a partir das três horas da tarde.

O jogo agradou tanto que logo espalhou-se pela comunidade, escapando ao controle - monopólio - do Barão, então a polícia, acreditando ser a idéia revestida de características de vício, proibiu o jogo, mas já estava tão popular que centenas de pessoas - banqueiros - vendiam as poules com os números referentes aos bichos, escolhidos pelo Barão de Drummond, atrelados ao sorteio da Loteria Federal, face a isto, os números tiveram que aumentar e como o número de bichos eram vinte-cinco, fez-se a divisão dos cem números da Loteria, cabendo assim quatro números para cada bicho. E foi na Bahia que surgiu a idéia de grupar bicho velho com bicho novo, isto é, tabela vertical e horizontal:

Figura 1: Animais x Números

\begin{tabular}{|l|l|l|l|l|l|}
\hline ANIMAL & $G^{32}$ & DEZENA & ANIMAL & GR & DEZENA \\
\hline AVESTRUZ & 01 & $01-02-03-04$ & GATO & 14 & $53-54-55-56$ \\
\hline ÁGUIA & 02 & $05-06-07-08$ & JACARÉ & 15 & $57-58-59-60$ \\
\hline BURRO & 03 & $09-10-11-12$ & LEÃO & 16 & $61-62-63-64$ \\
\hline BORBOLETA & 04 & $13-14-15-16$ & MACACO & 17 & $65-66-67-68$ \\
\hline CACHORRO & 05 & $17-18-19-20$ & PORCO & 18 & $69-70-71-72$ \\
\hline CABRA & 06 & $21-22-23-24$ & PAVÃO & 19 & $73-74-75-76$ \\
\hline CARNEIRO & 07 & $25-26-27-28$ & PERU & 20 & $77-78-79-80$ \\
\hline CAMELO & 08 & $29-30-31-32$ & TOURO & 21 & $81-82-83-84$ \\
\hline COBRA & 09 & $33-34-35-36$ & TIGRE & 22 & $85-86-87-88$ \\
\hline COELHO & 10 & $37-38-39-40$ & URSO & 23 & $89-90-91-92$ \\
\hline CAVALO & 11 & $41-42-43-44$ & VEADO & 24 & $93-94-95-96$ \\
\hline ELEFANTE & 12 & $45-46-47-48$ & VACA & 25 & $97-98-99-00$ \\
\hline GALO & 13 & $49-50-51-52$ & - & - & - \\
\hline
\end{tabular}

3Grupo 
"Com apenas três meses de existência e mesmo com o corte da subvenção federal, o Barão já tinha lucro suficiente para manter o zoológico, com o já conhecido jogo do bicho [...] o que se via, nas tardes ensolaradas dos domingos nas bilheterias do Jardim Zoológico de Vila Isabel, era um cavalheiro, acompanhado de sua mulher e três filhos, entregar um nota de cinco mil réis ao bilheteiro, pedindo: - um porco, uma vaca, um macaco, um camelo e um cachorro." (Soares, 1993).

\section{O Que Antecede à PARATODOS BAHIA}

Assim como no Rio de Janeiro e outras cidades do país, a Bahia também acolheu o jogo do bicho, não sendo diferente tanto na forma de atuação quanto na perseguição e repressão, sendo que as primeiras referências surgiram no Jornal A Tarde de julho de 1913. Para sobreviver por cem anos, foi imprescindivel a utilização dos mais diversos mecanismos de clandestinidade, desde anúncios em jornais até a utilização de códigos em igrejas enquanto o culto era desenvolvido.

A partir de 1941, através do Decreto-Lei n.3.688 do Código Penal Brasileiro, no capítulo VII das Contravenções Relativas à Polícia de Costumes, o jogo do bicho é citado, explicitamente, pela primeira vez como contravenção:

"Art 58. Explorar ou realizar a loteria denominada jogo do bicho, ou praticar qualquer ato relativo à sua realização ou exploração.

Pena: prisão simples, de quatro meses a um ano, e multa, de quatro mil cruzeiros a quarenta mil cruzeiros.

Parágrafo Único: Incorre na pena de multa, de quatrocentos cruzeiros a quatro mil cruzeiros, aquele que participa da loteria, visando obtenção de prêmio, para si ou para terceiro."

Como existiam muitos problemas na gestão do jogo, os banqueiros reuniram-se e criaram a UBB (União de Banqueiros da Bahia) em 1986, uma associação com a finalidade de:

evitar disputas para abertura de pontos, sendo determinado o respeito ao ponto já instalado;

evitar a inflação de pontos, ou seja, excesso de pontos em uma mesma localidade (bairro, rua, etc); 
organizar mais o jogo na cidade, uniformizando resultados e pagamentos de prêmios;

proporcionar maior intercâmbio e convivência entre os banqueiros, e cada novo atuante era convidado a participar da entidade.

\section{PARATODOS BAHIA: Sócio-Estrutura e Dinâmica Organizacional}

Em junho de 1990 surge a PARATODOS BAHIA, uma empresa sem registro legal, para gerenciar o jogo do bicho de forma monopolista, reunindo todas as bancas. Para a formação desta sociedade cada banqueiro tornou-se sócio-cotista a partir da quantidade de pontos que dispunha, isto é, no somatório total dos pontos de todas as bancas, o percentual de participação equivaleria ao percentual dos pontos em relação ao total. Devido à quantidade de bancas nas duas cidades (43), logicamente, os percentuais de participação não são altos, chegando mesmo a décimos, mas o suficiente para sanar as dificuldades enfrentadas por cada um quando atuavam isoladamente.

A PARATODOS BAHIA foi criada a partir de modelo existente em Fortaleza-CE, a primeira a organizar-se de tal forma e com os mesmos objetivos há mais de vinte anos. No intento de criar a empresa, alguns participantes da UBB viajaram até Fortaleza para conhecer o funcionamento, ao retornar implantaram e deram o mesmo nome, PARATODOS, como homenagem à pioneira.

\subsection{A ESTRUTURA}

A construção da estrutura organizacional da PARATODOS tem como base o regimento interno, discutido e aprovado em assembléia geral, o qual constantemente sofre alterações conforme mudanças conjunturais ou conveniências. No mesmo constam: estrutura da organização; composição societária; processo sucessório; modo de transmissão de cotas para herdeiros, sucessores e/ou outro(s) sócio(s)-cotista(s); bem como o que ocorrer no decorrer do tempo e outras providências. O documento é escrito e faz-se necessário devido às possíveis dúvidas que possam surgir em consequência das "falhas da memória" (informante).

A cúpula da PARATODOS BAHIA encontra-se estruturada da seguinte forma: os quarenta e três sócios-cotistas reúnem-se e elegem o presidente e o conselho fiscal para o mandato de dois anos com início sempre no primeiro dia do ano. O presidente eleito escolherá, dentre os cotistas, ao seu livre arbítrio os três diretores - Administrativo, Financeiro e de Apuração.

O Conselho Fiscal não tem poder de gestão, sua função restringe-se à auditoria das contas a cada dez dias; é composto de oito membros, sendo quatro vitalícios e quatro eleitos. Os conselheiros vitalícios são os quatro maiores eotistas, porém quando 
qualquer um desses assume funções executivas na empresa é afastado do Conselho, só retornando após abandono das mesmas. Nesse ínterim o cotista titular é substituído pelo subseqüente. Os membros do Conselho Fiscal são os mesmos do Conselho Deliberativo, responsável pela inspeção da gestão e convocação de assembléias.

Dentro da estrutura merece destaque o Departamento Médico/Social, cuja chefia está a cargo de uma Assistente Social. No início esse departamento era apenas para atendimento médico, o qual ocorria na sede e sem ônus ao atendido, com a função estratégica de atrair o cambista e o empregado para a empresa; com a ampliação do serviço e outras demandas por parte dos cambistas e empregados, sentiu-se a necessidade de um serviço social.

No início deste trabalho o Departamento Médico-Social era responsável pelo cadastro do funcionário, convênios médicos e atendimento médico na empresa, bem como serviço social. Atualmente, após reestruturação, o Departamento Médico desvinculou-se do Social, ficando o primeiro responsável pelo atendimento na própria empresa e emissão de guias para consultas externas; ao segundo cabe a gestão dos benefícios, convênios e atividades afins; já o cadastro de funcionário passou a ser função do Setor de Administração de Recusos Humanos e Pessoal, recém criado com a proposta de conhecer, treinar e desenvolver a mão-de-obra da PARATODOS BAHIA, tal setor está ao encargo de um funcionário, promovido ao cargo após conclusão de um curso de Pós-Graduação em Recursos Humanos. Todos os funcionários internos (com "vínculo" de emprego) e os externos (cambistas, sem "vínculo" de emprego) são assistidos pelos benefícios oferecidos, que vão do auxílio funeral, médico-hospitalar a atividades de congraçamento do tipo festa de aniversariantes do mês.

\subsection{POLÍTICAS E PRÁTICAS DE PESSOAL}

A Organização tem um sistema próprio de admissão, punição e demissão, mas no que se refere aos direitos trabalhistas, acompanha o que a legislação determina para as empresas legais. Sendo que os salários são superiores aos praticados no mercado para as profissões reconhecidas pelo Ministério do Trabalho ${ }^{33}$.

\subsection{SISTEMA DE INFORMAÇÕES}

O nivel de informatização é relativamente elevado, pois todos os setores já se encontram informatizados, eliminando substancialmente a quantidade de papéis em trânsito, até mesmo as poules do jogo são arquivadas por apenas cinco dias, prazo máximo para o cliente reclamar o prêmio.

\footnotetext{
${ }^{33}$ Serralheiro, Carpinteiro, Auxiliar de Escritório, Motoqueiro, Caixa, Servente, etc.
} 
Como a palavra está intimamente ligada à atividade e devido ao dinamismo do processo, observamos mesas limpas sem muitos documentos ou grande quantidade de arquivos. Existindo a intenção de instalar uma rede de computadores, disponível à diretoria, reduzindo-se ainda mais a circulação de papéis e, conseqüentemente, o vazamento de informações confidenciais.

\section{PARATODOS BAHIA: uma Organização em Rede}

Na construção deste trabalho sentimos a necessidade de analisar a questão da definição de rede, pois a mesma revela-se importante tanto do ponto de vista epistemológico quanto fenomenológico na abordagem das novas formas de organização.

O termo rede é originário do latim rete e segundo o Dicionário Aurélio (1986) a rede é um entrelaçamento de fios, cordas cordéis, arames, etc, com aberturas regulares fixadas por malhas, formando uma espécie de tecido, sendo utilizado para: apanhar (agarrar); armar ciladas, armadilhas; dar cobertura; salvar; amortecer choques decorrentes da queda; prender; dividir campos adversários; facilitar comunicação (telefone, rádio, televisão, etc); transportar; distribuir um organização em filiais; espionar; entrelaçar; canais de distribuição e dormir, ou seja, a rede é antiga e de amplo domínio público, podendo ser utilizada da forma que convier ao interessado.

Uma vez lançada às águas, a rede atrai, envolve e dificilmente o pescado escapa às suas malhas. $O$ termo extrapola o sentido físico e recebe outras conotações nas esferas da informática, da ciência social, da economia, da organização, da telefonia e etc. Pululam por todo tempo e espaço a formação de redes e conceituações. Cada ramo apropria-se e dá a denominação conforme a própria visão e entendimento, mas, inevitavelmente, poucas são as divergências quanto à idéia básica de rede. Para DeroyPeneau (1992), Neuschwander (1991), DeBresson e Amesse (1991), Freeman (1991) entre outros, rede significa o entrelaçamento, primeiro de pessoas que buscam algo em comum, favorecendo a emergência de atores (agitadores) responsáveis pelo prolongamento e emaranhamento de outras pessoas ou organizações no sistema; segundo, difunde a informação contribuindo para o enriquecimento, melhoramento e/ou aprimoramento das partes envolvidas, muito embora ocorra um relação de ganhaperde em que alguns perdem por algum tempo para que vários ganhem na maior parte do tempo.

No estabelecimento de redes os objetivos permeiam: troca de experiências e aprendizado; redução de custos e incertezas; aquisição de vantagem competitiva; procura de recursos humanos, suporte social ou apoio emocional; procura de bens (mobiliários, financeiros, imobiliários) e troca de informações.

As redes podem ser definidas também como "uma ligação próxima, selecionada e explicita, com parceiros preferenciais, num espaço de firmas com complementaridade e relações de mercado, tendo como objetivo a redução da estática e incertezas dinâmicas. Contribuindo também para a expansão de tecnologia em empresas sem 
familiaridade com a mesma, sendo a colaboração o meio mais rápido para acessar às capacidades tecnológicas pouco desenvolvidas dentro das firmas, e cujo desenvolvimento implica em largo investimento e tempo consideróvel" (Freeman, 1991).

Vários autores não consideram as redes fenômenos novos ou paradigmas emergentes, mas como mutante à medida que a sociedade evolui, a economia se aprimora e os nós se fortalecem. O sucesso das redes está nos fatores culturais: língua, educação, ideologia compartilhada, experiências e interesses comuns, mas a participação não acontece sem a obediência de algumas regras de adesão a um sistema de valores comuns, motivação e voluntariedade de cada um dos membros, circulação e transferência de informação, flexibilidade e rapidez da intervenção, aceitação de responsabilidades e riscos.

Os tipos de redes existentes variam sobremaneira, podendo ser: solidárias (sociais); de inovação; econômica; estratégica; organizacional e etc. No âmbito desta pesquisa a rede que mais nos interessa é a organizacional, assumindo hoje, características evoluídas e "maduras" em relação às formas anteriores.

Para evoluir até a formação de rede é preciso destacar que uma organização tradicional busca a racionalização da produção para uma melhor produtividade. $\mathrm{O}$ aprimoramento, inevitavelmente, destaca a superioridade do conhecimento e das técnicas, criando assim uma organização competitiva, que para manter-se, estruturou hierarquia, dividiu os papéis dos atores e dirigentes, bem como o trabalho; do lado externo, a relação tem formato assimétrico: a organização define o mercado e a sociedade; a comunicação ocorre de forma precária, não acatando do receptor reclames quanto ao teor, significado ou importância da mensagem. Face a tal quadro, surgem descontentamentos de todas as partes, ao infringir direitos humanos, sociais e comerciais, não abertura das fronteiras a novas idéias, abuso de autoridade, inflexibilidade e deterioração das relações ao violentar o ambiente social no qual está inserido.

De tudo isso, o resultado não poderia ser outro senão uma entropia, corroendo os alicerces perante à falta de visão e aceitação do novo e inesperado. As transformações sociais e econômicas ensejaram um novo ambiente baseado em constantes interações, trocas e intercâmbios entre as pessoas de tal forma que surge uma proposta de organização mais humanizada e flexível focalizando: "radical descentralização; interdependência intensa; expectativas demandadas; performance transparente; liderança distribuida; fronteiras rompidas; reciprocidade e redes intra e interorganizacional" (Hastings, 1993).

Nesse momento as definições de redes organizacionais apontam para um denominador comum: "organizaçães não são entidades autônomas, inteiramente livres nas escolhas do próprio futuro, elas investem na facilitação da comunicação intensa entre as pessoas, está ancorada em relações de interações com outras organizações, implementando variedades sociais, culturais e processos tecnológicos, fornecendo matéria-prima ou clientes elou serve como mercado para produtos ou serviços, podendo ser estabelecidas formal ou informalmente, assegurando estabilidade e reduzindo incertezas, resultando em evolução do poder e responsabilidades, e 
quebrando as fronteiras organizacionais" (Hastings, 1993; Alter \& Hagg, 1993).

Organizações em redes geram externalidades controláveis ou não: no primeiro caso os efeitos, em algumas situações, são previsíveis ou até mesmo estratégicas, como por exemplo a oligopolização; já o segundo aspecto fica por conta das instabilidades do próprio comportamento humano, insensível, por diversas vezes, a normas e regulamentos.

Organização de rede é um recurso institucional básico para lidar com o sistema de inovação. Redes podem ser vistas como forma de interpenetração de mercado e organização. Enfatiza-se a importância do relacionamento de cooperação entre firmas como uma chave de ligação do mecanismo de configuração de redes, incluindo "joint ventures", licenças, gerenciamento de contratos, subcontratação, compartilhamento de produção e colaboração em $P \& D$, e colocando um "spot" no desenho dessa nova organização, completamente enredada, verificamos mudanças estruturais, de gerências de processos e culturais operando diversas crenças e valores.

Impossível compreender a prática do jogo do bicho sem ter em mente o estabelecimento de redes para a sua sobrevivência e permanência. A partir do momento em que o jogo ultrapassa os limites do Jardim Zoológico e cai nas mãos dos cambistas, temos aí o segundo nó da rede que se iniciava, pois o primeiro já estava sacramentado com os visitantes/apostadores do Zôo.

As relações entre a PARATODOS e os demais grupos de interação é de dupla influência, em que tanto a organização interfere no ambiente como $o$ ambiente interfere na organização. Devido a esta situação, é que a PARATODOS tem como base de estruturação e atuação a flexibilidade: nenhuma estrutura ou forma é definitiva, nenhum tipo de aposta é rígido, pois o mercado e as trocas com o ambiente são também os responsáveis pela permanência da organização no espaço e no tempo. Em mais de cem anos de atuação, em nenhum momento o jogo do bicho deixou de ser praticado, sempre buscou uma maneira de estar em cena, não só pelos banqueiros, mas também pelos apostadores; a relação de cumplicidade é uma constante e a palavra um compromisso.

A análise de rede estima que o principal trabalho de pesquisa em ciências sociais consiste em estudar as estruturas sociais e suas consequências concretas, antes que uma estrutura social abstrata, analisando as relações entre os membros dos sistemas sociais e de descrever as estruturas que os reúnem.

Então o estudo de redes se situa no seio da família estruturalista, insistindo sobre as trocas, e se aproxima mais da economia de entradas/saídas e da física quântica, e nesse momento se transforma num paradigma novo para as mentalidades novas:

As relações estruturais têm um princípio mais poderoso que os atributos pessoais dos membros do sistema, pois muitas das correntes de pesquisa consideram os processos sociais como a soma de atributos;

As normas resultam das posições dentro dos sistemas estruturais de relações sociais, pois a partir da corrente sociológica aí reunida, as normas e os valores são interiorizados segundo a posição estrutural dos indivíduos que agem 
mecanicamente;

As estruturas sociais influenciam as relações duais, e estas relações mamtem-se porque os participantes são a base das estruturas sociais - parentesco, trabalho, amigos, rede de vizinhos e então a reciprocidade é realizada de forma mais eqüitativa sobre o conjunto de redes que ao seio de cada relação particular;

Sistemas sociais são as redes das redes, haja vista que os membros das redes pertencem a múltiplos círculos sociais, constituindo a trama dos sistemas sociais, pelo fato do mundo ser composto de redes e não de grupos (proletariado, burgueses, centro, periferia);

Na mobilização da rede, vários papéis lhes são atribuídos:

Promoção: no trabalho, é freqüente fazer uso da redes de relações pessoais (colegas, chefes ou professores) para conseguir promoção;

Mobilização Política: o que mobiliza e estrutura a atividade política é a articulação das relações dos grupos de pressão;

Convivência: pesquisadores têm dado maior atenção ao suporte social e as conclusões sugerem que as características das redes de um indivíduo podem afetar, significativamente, sua saúde, longevidade e bem-estar;

Proteção e de Auxílio Mútuo: a rede é uma condição indispensável à inserção de toda pessoa marginalizada para a sociedade e desejando aí se integrar, sejam exdrogados, ex-psiquiátricos, ex-detentos, assim a rede importa como fator de paz social;

Gestão: através da rede é possível encontrar novas estruturas de ação para contornar os tradicionais canais de comando.

Não se pode estudar redes separadamente de outros métodos das ciências sociais, pois é fruto do uso crescente dos resultados aproximados de teorias diferentes. Assim certos autores ilustram a influência estrutural - para o estudo de redes - sobre a cultura a partir de grandes sondagens tradicionais. Com os programas complicados, muito onerosos, eles agregam os dados, calculam os coeficientes de correlação e ensaiam testar os teoremas maiores, notadamente mensurar a força das relações. Concluem que as associações sociais dependem da posição social e da ocasião de contato. Os indivíduos não são unicamente influenciados por valores e normas, mas também pelas condições estruturais e vice-versa.

\subsection{Função da Rede}

Através da rede é possível: trocar experiências diversas; encorajar a aprendizagem sobre os clientes e fornecedores; ter o escopo para variadas aplicações e experimentações; reduzir o investimento e os esforços em técnicas irreversíveis. Logo, 
a rede não elimina, de todo, os riscos e as incertezas, embora sejam drasticamente reduzidos nos mercados secundários, nos comportamentos resultantes de oportunismo, bem como as incertezas tecnológicas relacionadas a configurações de sistemas e interface. As redes duráveis reduzem comportamentos oportunistas; mas as redes de inovadores envolvem normas, papéis, sistemas específicos de interface.

Contudo, lembra DeBresson e Amesse (1991), não se tem estudado as causas das falências das redes, a qual pode falir se houver: divergências de estratégias e poder; realização de incompatibilidade de propriedades ou mesmo a persistência de comportamentos oportunísticos. A única solução para impedir o processo de falência é a exclusão do(s) componente(s) fracos pelos demais: "Não é possivel, na rede, evitar a rigidez e todos os limites do sistema técnico; visto que nenhuma firma, grande ou pequena, poderá inovar ou sobreviver sem uma rede, pois muitas firmas têm ao menos cinqüenta por cento do valor de seus produtos, oriundo dos fornecedores externos".

O estabelecimento de uma rede é definitivamente um custo de risco, específico e irreversível. Em redes de aliạnças estratégicas ou aglomerações, as barreira à entrada são para futuros entrantes apenas ou para garantir a exclusividade sobre os direitos da tecnologia criada em rede; não funcionando nenhum dos anteriores, os custos de entrada serão menores para os futuros entrantes do que para os pioneiros da rede. Os membros da rede tendem a se tornar estáveis devido à irreversibilidade dos custos de implantação da rede e subseqüente escolha tecnológica. "Uma vez inovado com um parceiro, a tendência é inovar muitas vezes mais por causa"dos reduzidos custos de transação após o sucesso da primeira inovação" (DeBresson e Amesse, 1991).

\subsection{A Parceria Como Necessidade}

A parceria apresenta-se como indispensável entre os atores, tendo mais o espírito de cooperação que de controle, de defesa de interesses próprios ou apropriação de resultados. A parceria pode nascer da vontade de uma instituição ou de um ator líder que procura, pelo viés, dar mais amplitude à sua ação, até mesmo a exercer um certo controle.

"A parceria é marcada pela idéia de necessidade" (Delévaux e Gomez; 1991) de trabalhar junto, de multiplicar e de combinar as implicações de atores diversos, representando diferentes níveis de organização ou de recurso

Uma outra definição de parceria a tem como a colocação em comum dos recursos entre as instituições ou pessoas relevantes das instituições, as quais reconhecem a necessidade de apelar aos recursos dos outros para abordar os problemas identificados, coletivamente e então a solução é de cada uma das partes e não apenas de um só dos atores. 
A parceria é tida também como um sistema de relação firme, funcionando como um circuito (aproximado do modelo tradicional de organização técnico-administrativa) ou mais aberto às fronteiras ilimitadas, sendo que o esquema compreende um centro ou uma pessoa, com parcerias iguais, desiguais ou diferentes, e concepções dessemelhantes da natureza dos laços entre os atores.

Diante disso, há a necessidade de estabelecer as marcas que permitem aproximar as idéias de garantias, até mesmo de carta-contrato, balizando o funcionamento da parceria e a partilha legitima dos resultados, mediante as condições de reconhecimento da legitimidade das estratégias de um e outro, numa certa lucidez e transparência de comunicação, bem como a expressão clara de princípios, dos meios de balanço e de avaliação.

Para alguns autores a parceria é mais institucional e a rede é marcada pela informalidade, para outros, parceria e rede continuam hoje, 'coexistindo bem, e para funcionar as parcerias, necessita-se das redes efetivas, pois estas são o terreno da parceria, retomando um pouco o esquema em que a parceria se constrói sobre as afinidades e vontade de trabalho em comum. O que não é muito diferente nas redes.

\subsection{Virtualidade Organizacional em Rede}

Na sociedade contemporânea, devido à era da microeletrônica, a palavra virtual ${ }^{34}$ adquire força perante a fluidez dos sistemas e segundo Davidow e Malone.(1993), "uma corporação virtual parecerá quase sem contornos, com interface entre empresa, fornecedores e clientes, permeável e mudando continuamente". Os autores acentuam que do ponto de vista interno, tais empresas manterão suas estruturas em constante reformulação conforme as necessidades, incorrendo também numa alteração da configuração dos cargos.

A organização virtual tem sua sobrevivência ancorada na informação e nos relacionamentos ricos em confiança, para então elaborar produtos e serviços virtuais, os quais correspondam instantaneamente às necessidades e ambições dos consumidores ou prosumidores ${ }^{35}$.

"A meta das corporações virtuais é maximizar a energia de ligação entre elas e seus clientes. Isto é feito maximizando a satisfação do cliente e recrutando-o para uma relação de destino comum" (Davidow e Malone, 1993).

\footnotetext{
${ }^{34}$ possuir os poderes ou capacidades de outra coisa, apresentando-se de forma pujante: realidade virtual, computador virtual, produto virtual e, por fim, organização virtual

${ }^{35}$ Consumidores que produzem o que consumem (Toffler, 1980; apud Davidow e Malone, 1993).
} 
No bojo dessas transformações, mudarão também os funcionários da empresa virtual, pois a necessidade será de profissionais qualificados, confiáveis e com uma educação substancial, que pela imposição tecnológica, lidarão com processos mais sofisticados de informação, não cabendo, então, lugar para o não-alfabetizado e desprovido do senso para análise crítica e tomada de decisão.

A falta de fronteiras nas organizações virtuais, as conduz a uma situação de relacionamento próximo entre funcionários, executivos, clientes, fornecedores e governo, concomitantemente, o que difunde os limites de atuação de um e de outro, havendo apenas uma noção tênue da sua existência. Tal situação é típica ao jogo do bicho desde o momento em que 'saiu' do Zôo, pois a atividade passou a ser exercida em todos os lugares e ao mesmo tempo em lugar nenhum, pelo fato de não haver locais fixos para venda do jogo - os vendedores eram volantes ou então, no ponto escolhido: uma calçada, um botequim e etc., havia apenas um banco para sentar e uma caixa com divisórias para o material de trabalho.

Na criação da sua própria rede, o jogo do bicho evolui, refina-se nas práticas e como consequência dos 'nós', estabeleceu-se, na atualidade, em locais determinados e conhecidos, mas não perde o caráter virtual face à ilegalidade, responsável pelo tom das relações.

\subsection{PARATODOS BAHIA: Parceiros e Aliados}

\subsubsection{CLIENTES}

Os clientes (jogadores) articulam uma lógica própria para conseguir ganhar o prêmio, tal lógica advém de sonhos, palpites, intuição ou fatalidades ${ }^{36}$. Essa situação do imaginário simbólico permeará por todo o sempre a mente dos apostadores do jogo do bicho, pois tal idéia não se apresenta ao apostar nas loterias federais, estaduais ${ }^{37} \mathrm{e}$ privadas $^{38}$. O mundo do jogo do bicho está recheado de histórias de indivíduos que ganharam suas apostas por basearem-se apenas em um sonho, interpretando-o de forma diversa da manifestada, por exemplo: uma mulher sonhou que o marido a estava traindo com outra pessoa, no dia seguinte, imediatamente, dirigiu-se a uma banca, apostou no veado e ganhou (Soares, 1993).

\footnotetext{
${ }^{36} \mathrm{Ao}$ acompanhar um sepultamento, 0 indivíduo anota o número da lápide; na ocorrência de um acidente entre veículos, os números das placas são considerados como sinais de sorte para ganhar no bicho.

${ }^{37}$ Loto I, Loto II, Super Sena, Loteria Esportiva, Loteba e etc.

${ }^{37}$ Telesena, Papatudo, além desses, a Lei Zico estimulou o surgimento de casas de Bingo, atreladas a entidades esportivas visando incremento da renda para patrocinar práticas desportivas.
} 
Na relação com a clientela, o jogo do bicho desenvolve:

- Inovações atentas às necessidades dos clientes, tentando atender às ambições com novo serviço ou processo (cambista volante, multi mídia, fax, globo automático e etc) e que permitam o desenvolvimento do trabalho;

-Qualidade aos serviços através de uma relação mais próxima com o cliente, objetivando quantidade e complementação da rede;

-Inovações que contam com a presença (forte compromisso) da alta direção da organização para reforçar a rede;

- Talento dos seus empregados através da delegação de poder e autoridade, visando estimular a criatividade

Na história da atividade estabelece-se uma forte ligação entre o banqueiro do jogo e os apostadores, porque sem a proteção da lei quem jogaria no bicho sem saber se receberia o prêmio caso ganhasse? Então surge a importância da palovra para manter o compromisso; sem esta não haveria interesse em apostar. Tal fato se difundiu e alguns ditados foram cunhados: "palavra de bicheiro é lei", "no Brasil (1950) só havia três coisas que funcionavam: o exército, a Igreja e o jogo do bicho, e hoje (1995) só uma é honesta: o jogo do bicho".

"A palavra não vale mais do que o homem que a utiliza [...]. A ética da palayra, numa experiencia a cada dia renovada, afirma uma exigência da verdade. Trata-se de dizer a verdade, mas não há como dizer a verdade sem ser verdadeiro [...]. A paisagem cultural da humanidade é feita de palavras instituidas, palavras dadas, palavras mantidas, palavras declinadas" (Gusdorf, 1951: 121,123; apud Chanlat e Bedard, 1992).

\subsubsection{ORGANIZAÇÕES LEGAIS}

Embora as redes possam envolver o formal e as relações contratuais explícitas, elas não podem ser reduzidas ao contingente das cláusulas contratuais, porque as contingências:são imprediziveis. Portanto se as redes duram, elas envolvem também as formas leves de governo, reciprocidade informal e desenvolvimento da credibilidade.

Então é importante ressaltar que o estudo de rede comporta: a inovação da forma e interação entre as firmas que constituem o ambiente, pois o estudo de redes interorganizacionais habilita o cientista social a examinar como os mercados são endogenamente formados em uma estrutura competitiva específica, ao invés de assumir que os mercados existem com uma estrutura dada.

Rede é um modo de restruturação da vida social que liga os indivíduos entre eles, pois 
a visão que cada um tem é determinada pelo local considerado. Daí a questão: O jogo do bicho imiscuiu-se no cotidiano do brasileiro ou já estava, inconscientemente, imiscuído? Pode ser uma dúvida, mas o fato é que buscando integrar-se cada vez mais à sociedade formal, legal(izada), alia-se ou coliga-se a indivíduos, entidades e organizações legais, utilizando-se do dinheiro, resultante da atividade e cobiçado por todos, indistintamente, como forma de fazer valer sua existência.

No caso da PARATODOS BAHIA a penetração nesse mundo legal ocorreu, e continua, de uma forma forte e irreversivel. A organização transaciona com clínicas médicas e odontológicas, empresas de tíquetes para alimentação, vale-transporte, fornecedores dos mais diversos materiais, equipamentos e serviços, emissoras de rádio e jornais para divulgação do resultado das extrações, instituições filantrópicas e ainda consta no catálogo telefônico da cidade.

Obviamente esses relacionamentos são sempre de 'mão-dupla', isto é, há uma reciprocidade de influências entre a organização e o outro. São ambientes distintos, um contraventor e o outro legal, que ao se juntarem adaptam-se um ao outro para solucionar problemas e efetivarem negócios.

Desde a época que o jogo saiu do Zôo e foi proibido, surgiu a primeira inovação da atividade para a própria manutenção: atrelar o jogo aos resultados da loteria federal, isso dava mais credibilidade, por não ser facilmente manipulável. Durante algum tempo a PARATODOS teve uma das suas extrações atrelada ao resultado da Loteba (Loteria da Bahia), quando então algumas pessoas, responsáveis pela instituição pública, passaram a manipular os resultados, para com isso ganharem no bicho, pois já sabiam antecipadamente o resultado. Houve um escândalo com ampla divulgação na imprensa local, a partir daí a PARATODOS abandonou os resultados da loteria citada, a qual caiu em descrédito popular, restando ao governo do Estado desativá-la.

\subsubsection{Organizações Ilegais}

A partir do momento em que a Fiança ${ }^{39}$ foi estendida ao jogo do bicho, houve um "boom" no surgimento de bancas de bicho. Antes da Lei o que acontecia era a prisão por pelo menos dez dias, e isto funcionava como barreira à entrada de possíveis concorrentes. Com um contexto mais favorável, várias pessoas que atuavam em organizações criminosas ${ }^{40}$ também resolveram praticar o jogo; naquele momento mais de quarenta bancas atuavam em Salvador e Lauro de Freitas, proliferando-se inclusive para cidades do interior.

${ }^{39}$ Pagamento de determinado valor para que o preso seja posto em liberdade.

${ }^{40}$ Voltadas para atividades de crime envolvendo assaltos, 'gangs', sequestros, contrabando de armas, tráfico de drogas e etc. 
O nascimento da PARATODOS BAHIA modificou a forma de gestão do jogo do bicho, tratava-se de uma nova proposta, então mais forte e poderosa, tirando preocupações da mente dos sócios-cotistas e ratificando a posição do jogo do bicho na cidade.

O fato do jogo do bicho ser bancado, isto é, quando se faz a aposta já se sabe quanto ganhará em dinheiro caso acerte, levou os banqueiros a criarem uma rede para compartilhar o suporte das apostas, chamada de 'descarga', consistindo do seguinte: um jogador(a) aposta um valor ' $y$ ' em um milhar para o primeiro prêmio, caso acerte ganhará uma quantia ' $x$ ', caso o banqueiro considere difícil o pagamento de tal prêmio, o mesmo, então, repassa uma parte do valor apostado, ou seja, 'descarrega-o' em outra banca, ocorrendo assim uma divisão de lucros e prejuízos.

A PARATODOS BAHIA mantém três extrações (sorteios) diariamente: quatorze, dezoito e vinte-uma horas, em cada extração são feitos dez prêmios (10. ao 10o.) com quatro números cada um:

Figura 2. HORÁRIO DAS EXTRAÇÕES

\begin{tabular}{|c|c|c|c|}
\hline HORÁRIO & PREMIO & EXTRAÇÃO & DIA DA SEMANA \\
\hline 14 horas & $\begin{array}{l}1^{\circ} \text {. ao } 5^{\circ} . \\
6^{\circ} \text {. ao } 10^{\circ} \text {. }\end{array}$ & $\begin{array}{l}\text { Rio de Janeiro } \\
\text { PARATODOS }\end{array}$ & $\begin{array}{l}2^{\mathrm{a}} \cdot \text { a Domingo } \\
2^{\mathrm{a}} \cdot \text { a Domingo }\end{array}$ \\
\hline 18 horas & $\begin{array}{l}1^{\circ} \text {. ao } 5^{\circ} \\
1^{\circ} \text {. ao } 5 \text { o. } \\
6^{\circ} \text {. ao } 100 \text {. }\end{array}$ & $\begin{array}{l}\text { Rio de Janeiro } \\
\text { Loteria Federal } \\
\text { PARATODOS }\end{array}$ & $\begin{array}{l}2^{\mathrm{a}} \cdot, 3^{\mathrm{a}} \cdot, 5^{\mathrm{a}} \cdot, 6^{\mathrm{a}} \\
4^{\mathrm{a}} \text {. e Sábado } \\
2^{\mathrm{a}} \text {. a Sábado }\end{array}$ \\
\hline 21 horas & $\begin{array}{l}1^{\circ} \text {. ao } 5^{\circ} . \\
6^{\circ} \text { ao } 10^{\circ}\end{array}$ & $\begin{array}{l}\text { Rio de Janeiro } \\
\text { PARATODOS }\end{array}$ & $\begin{array}{l}2^{a} \cdot \text { a Sábado } \\
2^{a} \text {. a Sábado }\end{array}$ \\
\hline
\end{tabular}

É óbvio que o fato da PARATODOS BAHIA utilizar o sorteio do Rio de Janeiro implica em uma relação de, pelo menos, 'descarga' de apostas, sendo que a PARATODOS também recebe 'descarga' de bancas de cidades do interior da Bahia, as quais fazem uso dos sorteios acima descritos. O processo de 'descarga' é corriqueiro no ambiente do jogo do bicho, qualquer local onde exista jogo do bicho há 'descarga', que acontece via fax sempre antes do resultado das extrações (há um horário limite para recepção das informações), já o resultado dos sorteios feitos no Rio de Janeiro é transmitido, simultaneamente, via telefone, número a número. Como se constata, é uma rede de ilegais funcionando com eficiência e eficácia, tendo como sustentáculo a palavra (em todos os níveis e esferas), embora o uso dos recursos tecnológicos disponíveis no mercado seja intenso: computador, fax, câmeras de vídeo para circuito interno de vigilância e etc. 
As redes inter-organizacionais são reforçadas pela personalidade, cultura e simbolismos dos agentes participantes e para um bom funcionamento desse tipo de rede o que importa é: solidariedade; experiência compartilhada, sustentada pela proximidade geográfica; uma crença que requer proximidade e cultura comum; relacionamento limpo, o qual facilita a transmissão informal do conhecimento tácito, gerando assim uma vantagem localizada para essas redes inter-organizacionais.

\subsubsection{ESTADO}

\section{A) PODER EXECUTIVO}

As relações entre o jogo do bicho e o Estado sempre foram conflituosas, digamos também incestuosa, um misto de prazer e culpa. No momento em que a polícia iniciou as perseguições aos praticantes do jogo, instalou-se um conflito de conduta ética, ao proibir o 'bicho' e manter as loterias, ambos jogos de azar.

Nesses primórdios de ilegalidade, várias formas de escapar ao aparato repressor do Estado foram utilizados: encontros com senhas em Igrejas durante os cultos; informações numéricas em jornais de forma camuflada.

E por fim, não se sabe precisar quando, a polícia "cai nas graças" do jogo do bicho. Inicia-se um pacto comandado pela força do dinheiro, sem a certeza de qual das partes surgiu a proposta, se da polícia ou dos banqueiros do bicho, mas o fato é que esta relação se intensificou a ponto dos banqueiros serem informados, antecipadamente, das 'batidas' policiais, tendo a prerrogativa de escolher quais pontos deveriam ser flagrados, bem como alguns policiais passaram a dar segurança aos banqueiros visando complementar salário.

O jogo do bicho conforme o governo, estava aberto (praticado sem perseguições) ou fechado (proibido e perseguido), coincidentemente ocorria uma alternância entre aberto e fechado, e durante a gestão do Sr. Juracy Magalhães (1959-63) o jogo esteve aberto:

Revista O Cruzeiro, 05/09/1959

\section{"JURACY FECHA OS OLHOS AO JÔGO DO BICHO}

$\mathrm{E}$ os 'bicheiros' passam a ajudar os hospitais

...Juràcy pesou os prós e contras e decidiu: 'o jôgo do bicho continuará como era antes. Mas em vez de render para o bôlso dos inescrupulosos, vai render para as instituições de caridade'

Era essa a primeira vez que um Governador do Estado se responsabilizava pela tolerância de um jôgo proibido por lei. E a oposição abriu fogo. mas êle se limitou a responder, tranqüilamente: 
- Minha atitude obedeceu à inspiração de um realismo honesto, é um mal inextirpável. Embora proibido, o jôgo do bicho jamais deixou de existir, no País inteiro. Tenho bastante amadurecimento para saber quais os melhores caminhos para servir ao povo baiano. Os milhões que agora estão sendo canalizados para sustentar hospitais e casa de beneficência social iam para o bôlso de uma minoria constituída de inescrupulosos. Estou convencido: fiz um bem. Como a lei sêca, o jôgo proibido é o paraíso dos policiais desonestos e dos jornalistas venais".

Apenas no fim da entrevista o Governador cita a corrupção policial, sinonimada anteriormente de inescrupulosos; houve um reconhecimento tácito do envolvimento de um aparelho do Estado, e o Governador também admite a perpetuação da atividade "ilícita" através das doações a instituições filantrópicas formando aí mais um nó da rede lançada pelo jogo do bicho.

Atualmente a situação não é diferente, para que a PARATODOS BAHIA atuasse livremente e com segurança, houve um acordo com o Governador Waldir Pires (1987), o qual foi renovado com o governo seguinte, semelhante àquele feito entre Juracy Magalhães e os banqueiros da época.

Então de uma forma mais radical, "o funcionamento em rede é contrário à ética e ao bom funcionamento de uma gestão" (Morgenztern; 1991). Assim sendo, do ponto de vista Administrativo, os efeitos da rede resvalam para:

espaços possíveis de liberdade, mas não de transformação das organizações; modificação do discurso mais do que da prática;

indivíduos passadores de informações e facilitadores de iniciativas.

As diferentes visões e realidades territoriais dificultam a conexão entre as redes institucionais. Nesse contexto as redes existentes de alguns habitantes são consideradas redes negativas (prostitutas, toxicômanos e etc) ou seja, redes de excluídos, interditados de participar de outras iniciativas. É nessa lacuna das relações entre o Estado e Sociedade que o jogo do bicho penetra e desenvolve-se, pois as aspirações e objetivos dessas redes são autônomos em relação as demais redes e estas se constituem em urgência para resolver problemas específicos. Então, segundo Moergenztern (1991), as redes são denominadas como:

ação alternativa;

prática de rupturas referentes a ideologias de mudança e contra-poder; criação de um outro espaço além ou ao lado dos "poderes"; utopia social e signo de luta. 


\section{B) PODER LEGISLATIVO}

Até chegar a situação atual, por duas vezes especificamente registradas, houve movimentação no Legislativo, articulado pelo Executivo, no sentido de legalizar o jogo do bicho: em 1974 e 1984, no primeiro movimento esteve na dianteira o então Ministro Mario Henrique Simonsen, favorável à reabertura do jogo do bicho via oficialização, ou seja, gerido pela Caixa Econômica Federal e outra vez o Estado manifestou-se de forma contraditória e até mesmo com apropriabilidade indevida, pois visava tomar para si todos os pontos existentes no país, inclusive informatizando o jogo com ajuda da Data-Mec (empresa de processamento de dados do Rio de Janeiro), tal afirmação decorre da verdade de que concomitantemente havia a proposta de legalizar os cassinos, deixando-os em mãos privadas.

O segundo instante ocorreu em 1984, tendo à frente da proposta o então Ministro da Previdência Social o Sr. Jarbas Passarinho, sendo que dessa vez não se cogitava a oficialização do jogo, restringia-se apenas à legalização com operacionalização privada e recolhimento de contribuição especial para o INPS (Instituto Nacional da Previdência Social).

Conforme o Jornal A Tarde de 31/05/84, após delegação de poderes do então Presidente da República, João Figueiredo, ao Legislativo para tratar da questão, a mesma foi transformada em projeto pelo deputado goiano Siqueira Campos, recebendo parecer favorável do relator, deputado Nilson Gibson (PDS-PE), com substitutivo no qual a Previdência Social seria o único órgão a ser beneficiado com a legalização, bem como a exclusão do jogo do bicho da relação das contravenções penais estava condicionada a satisfação de três princípios:

1. que os 'bicheiros' pedissem autorização à Caixa Econômica Federal para o funcionamento das bancas;

2. que dez por cento da arrecadação bruta mensal das apostas fossem destinados à Previdência Social;

3. que os 'bicheiros' regularizassem o patrimônio adquirido ilicitamente através do jogo do bicho no prazo máximo de três anos, isentos de qualquer penalidade.

Tal projeto ainda teria uma tramitação a cumprir dentro do Congresso Nacional negociações, debates, entrada em Comissões e etc - porém, pelo que se constata atualmente, não ocorreu a legalização, embora o relator do projeto fosse favorável e, na época, advogado da Associação dos Cambistas de Pernambuco. Ficando então a questão: por quê?

Trazendo para a Bahia o debate acerca do tema dentro da Assembléia Legislativa, verificamos uma série de manifestações, através de discursos parlamentares, favoráveis e contrárias ao jogo do bicho. No ano de 1984, mais precisamente em 17 de maio, o deputado Murilo Leite (PMDB) subiu à tribuna para abordar a questão do jogo do bicho na Bahia, no seu discurso o deputado acusou o então Governador, João Durval 
(PDS), de confesso "acobertador do jogo do bicho na Bahia", citando a amizade com os banqueiros de bicho, através da qual fora selado um acordo de apoio durante a campanha para o governo em troca da não repressão policial à atividade durante o mandato. Em seguida o deputado Eliel Martins (PDS) contra-argumentou, lendo em plenário um requerimento à mesa da Câmara de Vereadores de Salvador, do ano anterior, enviado pelos edis do PMDB, no qual pedia-se que fosse oficiado o Governador solicitando-lhe "a necessária compreensão de sentimento de solidariedade humana para com as pessoas que têm como seu uinico meio de sobrevivência e de sua família a oportunidade de bancar ou cambiar o popular jogo do bicho, a exemplo do que já vem ocorrendo em outras capitais, onde os governos vêm tolerando a sua prática exatamente por questões de interpretação de caráter social" (Joaquim Costa; 1983).

Após toda essa discussão, o Governador João Durval decidiu implementar uma 'caça' aos banqueiros e seus auxiliares, saindo no Jornal A Tarde (23/05/84) a seguinte manchete:

"Governo decide acabar com 'jogo do bicho' e comunica à $A L "$

É preciso destacar que todas as tentativas de legalizar o jogo do bicho, sempre condicionou-se tal ato a uma contrapartida em favor da Previdência Social, em nenhum momento a discussão gira em torno da legalização única e simplesmente sem condicionamentos e com isso não evolui-se no processo. Quando perguntado a respeito do porquê da não legalização da atividade, um sócio-cotista responde ironicamente: "legalizar o jogo do bicho significa tirar uma segunda renda de 'muita gente"."

\section{C) Poder Judiciário}

Na sua démarche não é raro o momento em que o jogo do bicho se debate com o judiciário, seja por conta dos crimes com mortes, do contrabando de armas e drogas ou da própria contravenção.

No ano de 1994, a Juíza Denise Frosard, na cidade do Rio de Janeiro, foi figura de destaque pelo fato de ter condenado à prisão todos os membros da cúpula do jogo do bicho daquela cidade, sob a alegação de formação de quadrilha. Num outro momento, no mesmo ano, houve uma efervescência no país de caçada aos banqueiros de bicho, em decorrência da descoberta de provas concretas do envolvimento de policiais com o jogo do bicho no Rio de Janeiro e a possibilidade de ligações entre banqueiros do bicho e operações de contrabando de armas s tráfico de drogas. Todo esse processo estava acompanhado pelo Procurador Geral de Justiça do Estado do Rio de Janeiro, Antônio Carlos Biscaia. Em entrevista concedida à revista Visão em 1991, o mesmo afirmou: "Na essência, ele (jogo do bicho) é rigorosamente inocente. O jogo de números, vinculado a animais, em nada se diferencia - a não ser pela maior lucratividade - da Loteria Federal ou da Loto. De resto, está entranhado na cultura 
desse povo..., na realidade, sua ilegalidade fez com que nascesse uma organização clandestina perfeitamente estruturada e funcionando em moldes capazes de fazer inveja a muitas organizações legais"

Quando questionado sobre a fraqueza das instituições para punir a atividade, ele diz: "O Poder Judiciário precisa ter provas que são obtidas pela policia. No entanto, eu noto que a policia parece não ter interesse em apurar as atividades criminosas relacionadas com o jogo do bicho [...] Nós tivemos um banqueiro do jogo do bicho, o Carlinhos Maracanã, contra o qual haviam provas suficientes de sua participação num homicídio. Ainda assim ele foi absolvido no Tribunal do Júri por sete a zero. E o que é o Tribunal do Júri? É a própria sociedade julgando. Isso quer dizer que esses banqueiros, contraventores criminosos, são figuras que contam com a simpatia da população".

Em nossa pesquisa não verificamos ocorrer em Salvador uma possível relação com tráfico de drogas ou contrabando de armas taI qual ocorre no Rio de Janeiro. Em nenhum momento a imprensa local afirma ou alude existir ligações entre o jogo do bicho local e atividades criminosas.

Um imbróglio judicial enfrentado, com maior frequência, pela PARATODOS está na área trabalhista, pois vários apontadores ou escreventes - pessoas que anotam as apostas - vão à Justiça do Trabalho reivindicar 'direitos' trabalhistas. É uma situação desconfortável para a Justiça, haja vista a realidade que lhe é colocada: um trabalhador contraventor buscando auxílio da lei, pois antes de tudo é cidadão, e esta não pode, por força das normas, ajudá-lo pelo fato de não ser, o trabalho executado no jogo do bicho, uma profissão reconhecida pelo Ministério do trabalho.

Embora a PARATODOS BAHIA afirme pagar todos os direitos trabalhistas aos demitidos, cumprindo a palavra, alguns poucos não se conformam e vão adiante; vale ressaltar que essas pessoas reclamantes junto à Justiça do Trabalho têm uma história curta no jogo do bicho, pelo fato de não terem vivenciado os períodos mais agitados da repressão à atividade e portanto não há uma relação de gratidão entre banqueiro e empregado, caso diferente para aqueles que vivem do jogo há longas datas.

\section{Conclusões}

Realizar um trabalho de investigação acerca do jogo do bicho não é fácil, principalmente por se tratar de um tema complexo e contraditório desde a prática até as formas de interação com o ambiente. Devem ser consideradas, também, as dificuldades de bibliografias adequadas ao tema; caracteristicamente brasileiro e com poucos trabalhos publicados. Superadas estas dificuldades, tentamos responder a seguinte problemática: como uma organização contraventora sobrevive e permanece no tempo? 
A primeira resposta passa pela hipótese do jogo como fator de sedução do imaginário popular, visto serem dotados de imaginação simbólica e alegórica aqueles que se dispõem a jogar, especialmente no jogo do bicho. Constatamos que diferente do que acontecia tempos atrás, o jogador do bicho não mais o pratica com a esperança de enriquecer, mas sim com a intenção de vencer, ou melhor, ganhar, "acertando no bicho' através da construção de uma lógica própria conforme intuição e sonhos.

Tal situação ocorre com mais freqüência entre as pessoas pertencentes as classes mais baixas da sociedade, que devido à pobreza e intencionando ganhar um 'dinheirinho' a mais para a alimentação da semana, arrisca o dinheiro do pão daquele dia ao jogá-lo no bicho em função de um palpite oriundo da intuição ou de um sonho. No momento em que ganha no bicho, uma enorme sensação de satisfação invade o jogador, porque venceu e diante de tantas derrotas na vida cotidiana, este vencer representa muito mais do que receber o dinheiro ou saciar a fome nos dias seguintes, e este aspecto é mais intenso naqueles possuidores do vício de jogar.

A segunda resposta alicerça-se na suposição da virtualidade e redes organizacionais estabelecidas pela PARATODOS na gestão do jogo do bicho. A PARATODOS tem uma extensa malha de relações tanto no mundo legal quanto no ilegal contraventor $\mathrm{e}$ essa rede só é possível a partir da inexistência de fronteiras rígidas entre a organização e a sociedade de inserção, destacando então o caráter virtual de um empreendimento contraventor dotado de extrema flexibilidade para adaptar-se às constantes mudanças do ambiente, principalmente em relação às necessidades dos clientes. A interface da organização clientes, fornecedores, Estado e sociedade gera externalidades tanto para àquela quanto para os demais, pois a confrontação de idéias, culturas e valores éticomorais origina uma nova realidade distinta para ambos os mundos: legal e ilegal.

Num primeiro momento sentimos a força da contradição entre o legal e o ilegal, por haver uma fragilidade comportamental e atitudinal em relação à prática do jogo do bicho, uma vez que alguns recriminam, outros aprovam, outro tanto aceita ou rejeita sob certas 'condições', e o resto, joga. O jogo do bicho é uma ação social, por se tratar de uma conduta desenvolvida pelos indivíduos, associada a um sentido subjetivo, que ao interagir com outros atores, pode revestir-se ou não de uma linguagem simbólica. A situação real de convivência do imaginário simbólico, motivando os jogadores, com a ilegalidade imposta, gera conflitos na sociedade e um clima de instabilidade social, o que é agravado pelas práticas criminosas comprovadamente associadas ao jogo do bicho; especialmente no Rio de Janeiro.

Como decorrência de tal instabilidade - proibição e conivência, surgiu a PARATODOS BAHIA organizando a atividade e implantando uma nova proposta, no cenário baiano, de gestão do jogo do bicho. Ao analisar a organização descobre-se uma forma brasileira de administrar eficaz, destituída dos modelos e tecnologias gerenciais importadas - administração participativa, qualidade total, reengenharia e etc - e carregada dos valores morais dessa sociedade. Encontra-se de tudo: paternalismo, protecionismo, vícios, família, formalismo, informalismo, regras, moralidade, perversidade organizacional, favor, comprometimento, 'jeitinho' e tudo o mais que se 
manifeste no ambiente social. Essa capacidade de costurar a diversidade da cultura local é que dá a PARATODOS o caráter de virtualidade devido à flexibilidade para lidar com o diverso e face à ausência de limites claros na interface da organização com as demais, pois a rede construída pelo jogo do bicho, com o passar do tempo, sofreu incrementos - entrada de novos componentes - e refinou-se - na prática da filantropia, estendendo seus nós a espaços antes impenetráveis.

A PARATODOS amplia a penetração no mundo legal via rede, utilizando como estratégia a força financeira; o que modifica os comportamentos de oposição, criando uma dependência em relação à organização que, também, ocupa espaços, em princípio, inerentes ao Estado, ao assumir algumas obrigações sociais - manutenção de creches, asilos, instituições e agremiações sociais e religiosas, complementação salarial de funcionários de aparelhos do Estado -, exercendo assim, uma filantropia que desequilibra posturas preconceituosas antes adotadas pelos indivíduos que hoje mitigam um relacionamento estreito com contravenção instituida. E nesse sentido, a sobrevivência e manutenção da organização, bem como o estabelecimento das conexões passa também por uma liderança essencialmente carismática.

Especulamos, no entanto, que numa situação de legalidade, haja transformações do modus operandi organizacional de liderar, porque o formalismo regulará as relações, tomando o espaço hoje ocupado pela palavra. Sendo que, a alteração de contraventora para Pessoa jurídica porá em xeque não só a própria organização como também a rede por ela estabelecida, no momento em que os nós forem orientados por uma formalidade rígida e inflexível na adaptação às mudanças. Concluímos, então, que o caráter contravencional da atividade atua como estimulante ao funcionamento da mesma, por instigar nas pessoas a sensação de envolvimento com o proibido.

Para concluir, o estudo da PARATODOS BAHIA, do ponto de vista organizacional, revelou-se empolgante e desafiador ao evidenciar aspectos peculiares dessa atividade tão brasileira. Acredita-se que a análise de organizações contraventoras como a PARATODOS possam fornecer pistas do "jeito" brasileiro de gerir; já que as mesmas absorvem muito das culturas locais, refletindo-as e para elas contribuindo.

\section{Referências Bibliográficas}

CHANLAT, Alain e BEDARD, Rennée. Palavras: a ferramenta do executivo. Tradução por Mauro Tapias Gomes. In: CHANLAT, Jean-François. OIndividuo na Organização: dimensões esquecidas. Tradução por Arakcy Martins Rodrigues. São Paulo: Atlas, 1992. p.125-148. Título original em francês: La gestion, une affaire de parole. 
DANTAS, M. Olodum: de bloco afro a holding cultural. Salvador: Edições Olodum, 1994.

DAVIDOW, William \& MALONE, Michael S. A Corporação Virtual. São Paulo: Pioneira, 1993.

DEBRESSON, Chris \& AMESSE, Fernand. Networks of Innovators: a review and introdution to the issue. Research Policy, North Holland, n.20, p.363-379, 1991.

DELÉVAUX, Cécile e GOMEZ, Rosita. Partenariat et Réseaux. In: Le Clair-Obscur des Réseaux, Revista Pour, Paris, n.132, dez/1991.

DEROY-PINEAU, Françoise. Réseaux Sociaux et Mobilisation de Ressources. In: Le Clair-Obscur des Réseaux, Revista Pour, Paris, n.132, dez/1991.

FISCHER, Tânia e SANTOS, Jair N. $O$ "Capo" no Jogo do Bicho: uma organização PARATODOS. Organizações \& Sociedade, Salvador, v.2, n.3, p.121-129, dez/ 1994.

FRANCA, Genauto et alli. Em nome de Deus, uma ordem na pólis: O Mosteiro de São Bento. Organizações \& Sociedade, Salvador, v.1, n.1, 1993.

FREEMAN, C. Networks of Innovators: a synthesis of research issues. Research Policy, North Holland, n.20, p.363-379, 1991.

HASTINGS, C . Making Sense: understanding the different aspects of networking. The New Organization. Londres: Sage, 1993. p.12-33.

MARTIN-DUPRAY, Muriel. Réseaux Sociaux et Réseaux Économiques. Le ClairObscur des Réseaux, Revista Pour, Paris, n.132, dez/1991.

NEUSCHWANDER, Claude. Les Réseaux et les Acteurs. In: Le Clair-Obscur des Réseaux, Revista Pour, Paris, n.132, dez/1991.

OLIVEIRA, Juarez de. Novo Código Penal. 23a. edição. São Paulo: Saraiva, 1985.

PESQUISA em jornais: A Tarde, Correio da Bahia, Bahia Hoje e Tribuna da Bahia (Bahia); Folha de São Paulo (São Paulo); O Globo e Jornal do Brasil (Rio de Janeiro) e em revistas: Veja e Isto É (São Paulo); Manchete e O Cruzeiro (Rio de Janeiro). 
PINTO, Luís Fernando. PARATODOS BAHIA: diagnóstico e solução de problemas. Salvador: mimeo, 1995 ;

RISÉRIO, A. Carnaval Ijexá. Salvador: Currupio, 1992.

SIQUEIRA, M. L. As Dimensões Organizativas da Cultura Afro-Baiana em Salvador. In: FISCHER et al. Poder Local, Governo e Cidadania. Rio de Janeiro: Fundação Getúlio Vargas, 1993.

SOARES, Simone Simões Ferreira. O Jogo do Bicho: a saga de um fato social brasileiro. Rio de Janeiro: Bertrand Brasil, 1993.

VIANNA, Hildegardes. O Jogo do Bicho. Salvador: A Tarde, 26/11/1990. 